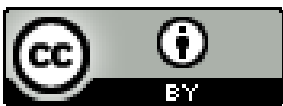

\title{
LUTA ANTIRRACISTA E DEMOCRACIA RACIAL NO SÉC. XX: O LEGADO DO JORNAL QUILOMBO: VIDA, PROBLEMAS E ASPIRAÇÕES DO NEGRO (1948-1950)
}

\author{
Tailane Santana Nunes ${ }^{1}$ \\ Wilson Rogério Penteado $\mathrm{Jr}^{2}$
}

Resumo: Logo após o processo abolicionista, no início do século XX, uma mobilização de negros alfabetizados na luta contra o racismo deu origem ao que atualmente conhecemos como imprensa negra. Por meio da produção de jornais, revistas e folhetins independentes, afro-brasileiros denunciavam o racismo cotidiano e afirmavam sua identidade racial. O Jornal Quilombo figura dentre estes com um importante valor cultural. Dedicado a documentar as ações do teatro negro e as principais questões relativas à comunidade afro-brasileira, Quilombo configurou-se enquanto um instrumento de diálogo permanente com organizações negras no Brasil. Através de uma revisão bibliográfica, o presente ensaio teórico propõe-se a contextualizar a atuação do Jornal Quilombo entre os anos 1948-1950, destacando o importante papel desenvolvido pelo folhetim no combate ao "mito" da democracia racial e, consequentemente, na luta antirracista no Brasil.

Palavras-chave: Luta-antirracista; Jornal Quilombo; Imprensa Negra; Democracia Racial

\section{ANTI-RACIST STRUGGLE AND RACIAL DEMOCRACY IN THE 20TH CENTURY: THE LEGACY OF JORNAL QUILOMBO: NEGRO LIFE, PROBLEMS AND ASPIRATIONS (1948-1950)}

Abstract: Soon after the abolitionist process, at the beginning of the 20th century, a mobilization of literate blacks in the fight against racism gave rise to what we now

\footnotetext{
${ }^{1}$ Graduada em Ciências Sociais pela Universidade Federal do Recôncavo da Bahia (2019). Mestranda do Programa de Pós-Graduação em Ciências Sociais - Cultura, Desigualdade e Desenvolvimento/ PPGCSUFRB. Desenvolve pesquisas que versam sobre a trajetória social de Abdias Nascimento e Movimento Negro Brasileiro. E-mail: tailanenunes@ outlook.com

${ }^{2}$ Graduado em Ciências Sociais, com ênfase em Antropologia Social pela UNICAMP (2001). Mestre em Antropologia Social (2004), e Doutor em Antropologia Social (2010) pela mesma instituição, UNICAMP. É Professor Associado de Antropologia na Universidade Federal do Recôncavo da Bahia. Email: penteadowjr@ufrb.edu.br
}

Revista da ABPN • v. 12, n. Ed. Especial - Caderno Temático: "Africanos, escravizados, libertos biografias, imagens e experiências atlânticas” • agosto de 2020, p. 694-710 
know as the black press. Through the production of independent newspapers, magazines and serials, the Fro-Brazilians denounced daily racism and affirmed their racial identity. The Jornal Quilombo is one of these with an important cultural value. Dedicated to documenting the actions of the black theater and the main issues related to the AfroBrazilian community, Quilombo was configured as an instrument of permanent dialogue with black organizations in Brazil. Through a bibliographic review, this theoretical essay proposes to contextualize the performance of Jornal Quilombo between the years 1948-1950, highlighting the important role developed by the booklet in combating the "myth" of racial democracy and, consequently, in the anti-racist struggle in Brazil.

Keywords: Anti-racist struggle; Quilombo newspaper; Black Press; Racial Democracy.

\section{LUCHA ANTIRRACISTA Y DEMOCRACIA RACIAL EN EL SIGLO XX: EL LEGADO DEL JORNAL QUILOMBO: VIDA, PROBLEMAS Y ASPIRACIONES DE LOS NEGROS (1948-1950)}

Resumen: Poco después del proceso abolicionista, a principios del siglo $\mathrm{XX}$, una movilización de negros alfabetizados en la lucha contra el racismo dio lugar a lo que ahora conocemos como la prensa negra. A través de la producción de periódicos independientes, revistas y series, los brasileños denunciaron el racismo diario y afirmaron su identidad racial. El Jornal Quilombo es uno de estos con un importante valor cultural. Dedicado a documentar las acciones del teatro negro y los principales problemas relacionados con la comunidad afrobrasileña, Quilombo se configuró como un instrumento de diálogo permanente con organizaciones negras en Brasil. A través de una revisión bibliográfica, este ensayo teórico propone contextualizar el desempeño de Jornal Quilombo entre los años 1948-1950, destacando el importante papel desarrollado por el folleto en la lucha contra el "mito" de la democracia racial y, en consecuencia, en la lucha antirracista en Brasil.

Palabras clave: lucha antirracista; Periódico quilombo; Prensa negra; Democracia racial.

\section{LUTTE ANTIRACISTE ET DÉMOCRATIE RACIALE AU XXE SIÈCLE: L'HÉRITAGE DE JORNAL QUILOMBO: VIE NOIRE, PROBLÈMES ET ASPIRATIONS (1948-1950)}

Résumé: Peu après le processus abolitionniste, au début du XXe siècle, une mobilisation des Noirs alphabétisés dans la lutte contre le racisme a donné naissance à ce que nous connaissons aujourd'hui sous le nom de presse noire. Par la production de journaux, magazines et périodiques indépendants, les Fro-Brésiliens ont dénoncé le racisme quotidien et affirmé leur identité raciale. Le Jornal Quilombo est l'un d'entre eux avec une valeur culturelle importante. Dédié à la documentation des actions du théâtre noir et des principaux enjeux liés à la communauté afro-brésilienne, Quilombo a été configuré comme un instrument de dialogue permanent avec les organisations noires du Brésil. À travers une revue bibliographique, cet essai théorique propose de

Revista da ABPN • v. 12, n. Ed. Especial - Caderno Temático: "Africanos, escravizados, libertos biografias, imagens e experiências atlânticas” • agosto de 2020, p. $694-710$ 
contextualiser la performance de Jornal Quilombo entre les années 1948-1950, en soulignant le rôle important développé par la brochure dans la lutte contre le «mythe» de la démocratie raciale et, par conséquent, dans la lutte antiraciste au Brésil.

Mots-clés: lutte antiraciste; Journal Quilombo; Presse noire; Démocratie raciale.

\section{INTRODUÇÃO}

"O Brasil é renomado mundialmente por sua democracia racial”. A afirmação feita pelo intelectual Charles Wagley em sua introdução no primeiro volume de investigações sobre as relações raciais no Brasil financiados pela $\mathrm{UNESCO}^{3}$ definiu, segundo Antônio Guimarães, a síntese do pensamento de toda uma época e de toda uma geração de cientistas sociais.

De acordo com Guimarães (2002), uma série de artigos escritos por afroamericanos entre 1910 e 1940, reafirma a crença generalizada num Brasil sem discriminações raciais, uma espécie de democracia racial onde a "raça" não definia o mérito individual. A ideia de uma nação mestiça racialmente harmoniosa, sem linhas de cor, ou seja, sem barreiras que impedissem a ascensão de pessoas de cor, fora largamente difundido como o diferencial brasileiro frente os confrontos raciais explícitos encontrados em outros países. Segundo esta representação, o Brasil não teria uma raça definida, seja ela branca, preta ou índia, erámos um povo mestiço.

Num constante afastamento dos ideais da ditatura varguista e do fascismo/nazismo derrotados na segunda guerra mundial, a noção de democracia juntamente com os conceitos de povo e nacionalidade configuram enquanto centrais no léxico político brasileiro na década de 50 (GUIMARÃES, 2002). Buscava-se reconstruir a identidade nacional sob as bases de uma narrativa luso-brasileira que exaltava uma particularidade da nação brasileira: o alto grau de miscigenação racial. Supostamente, o "caldeirão étnico" brasileiro absorvia e abrasileirava as diversas culturas dos diferentes povos que compunham a população e atestavam certa

\footnotetext{
${ }^{3}$ No início da década de 1950, a Organização das Nações Unidas para a Educação, a Ciência e a Cultura (UNESCO) patrocinou um conjunto de pesquisas sobre as relações raciais no Brasil. A origem deste projeto estava associada à agenda antirracista formulada pela Unesco no final dos anos 1940 sob o impacto do racismo e da Segunda Guerra Mundial. O objetivo do projeto era "determinar os fatores econômicos, sociais, políticos, culturais e psicológicos favoráveis ou desfavoráveis à existência de relações harmoniosas entre raças e grupos étnicos".
}

Revista da ABPN • v. 12, n. Ed. Especial - Caderno Temático: "Africanos, escravizados, libertos biografias, imagens e experiências atlânticas” • agosto de 2020, p. 694-710 
"brasilidade mestiça" como unidade da diversidade. Segundo Guimarães, tudo que não era genuinamente luso-brasileiro, misturado, sincrético era visto como um perigo para a jovem democracia brasileira. Dentro desta perspectiva,

Os negros e índios, na política republicana, são apropriados como objetos culturais, símbolos e marcos fundadores de uma civilização brasileira, mas tem negado o direito a uma existência singular plena como membros de grupos étnicos. Esses são marcos da fronteira da civilização brasileira, remanescentes dos antepassados que criaram a nação, restos e vestígios das origens coloniais (GUIMARÃES, 2002, p. 121).

Esta configuração funda e solidifica o sentimento de pertença à nação brasileira que buscava refletir uma "brasilidade inclusiva e aberta, capaz de integrar em seu interior harmonicamente as diferenças raciais (COSTA, 2002, p. 45)". Tal ideal de "brasilidade" ou paraíso racial começou a entrar em descredito quando surgem organizações negras, principalmente durante a Nova Republica em 1945, que influenciariam a vida nacional em termos culturais, políticos, e ideológicos. Tais instituições tornavam públicas as discussões em torno da discriminação racial no Brasil e quebravam o gelo sobre os modos como o racismo operava na vida de afro-brasileiros e as inconsistências da tão promulgada democracia racial

. O jornal Quilombo - Vida, problemas e aspirações do negro, figura com destaque dentre estas organizações durante o período 1948-1950. Quilombo surge enquanto fruto do Teatro Experimental do Negro fundado em 1944, que através de suas peças buscavam desenvolver "a valorização social do negro através da educação, da cultura e da arte (NASCIMENTO, 2004, p 198)”. Agindo sobre duas frentes, o periódico denunciava os efeitos do preconceito racial ao tempo que empreendia uma tomada de consciência do negro sobre a configuração social em que estava inserido.

Responsável por introduzir uma essência negra, culturalmente africana, o jornal Quilombo conseguiu “dar vazão às ideias, propostas e representações de intelectuais (negros e brancos) e ativistas negros a respeito da população afro-brasileira dos anos 1940 e 1950 (ROSA, 2007, p. 84)". Ao refletir sobre a trajetória social do jornal Quilombo, busca-se neste ensaio evidenciar a contraposição ao "mito" da democracia 


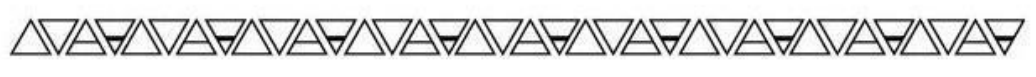

racial que o Jornal propõe através de sua atuação e, consequentemente, sua importância na luta antirracista no Brasil.

\section{UM JORNAL NEGRO}

Trazendo perspectivas inovadoras para o pensamento social brasileiro, o jornal Quilombo tinha raízes: a imprensa negra paulista. Formado por negros escolarizados que utilizavam a escrita e oralidade como ferramenta de luta, a imprensa negra é academicamente reconhecida como um movimento político onde os jornais eram destinados a refletir acerca das questões raciais e sociais. Tais jornais eram essenciais para a população negra, já que os folhetins tradicionais não veiculavam informações especificas para a comunidade negra. Segundo a definição de Bastide,

É uma imprensa que só trata de questões raciais e sociais, que só se interessa pela divulgação dos fatos relativos à classe da gente de cor. É uma imprensa adicional. Esses jornais procuram, primeiramente agrupar os homens de cor, dar-lhes o senso de solidariedade, encaminhá-los, educá-los a lutar contra o complexo de inferioridade, superestimando os valores negros. É, pois, um órgão de educação. É um órgão de protesto; para lutar contra o preconceito, o negro terá que se insurgir e o jornal servirá para fazer ouvir o seu protesto (BASTIDE, 1951. p.51).

Durante o período em que ficaram ativos, contabiliza-se mais de 30 folhetins circulando regularmente em São Paulo. Foram publicados títulos como O Menelick (1915), A Liberdade (1918), e Clarim da Alvorada que foi lançado em 1924 e fora do estado, títulos como a Raça (1935) publicada em Uberlandia/MG. Inseridos na luta contra o racismo, estes periódicos abarcavam as discussões de interesse dos negros brasileiros, como o combate à discriminação racial nos mais diversos espaços sociais e a integração dos negros no projeto de desenvolvimento do Brasil.

Segundo Pinto (2006), por meio dos jornais da imprensa negra do séc. XIX, “os afro-brasileiros conseguiram formular uma fala própria e torná-la pública. Ainda que não tenham alcançado simultaneamente todo o território nacional, esses impressos são parte do esforço coletivo de controlar os códigos da dominação e subvertê-los (PINTO, 2006, p.70)”. Compromissadas, as páginas dos jornais eram veículos de denúncias sobre 
a velada segregação racial que imperava no país e impossibilitava o acesso do negro em ambientes públicos, como hotéis, clubes, restaurantes e cinema.

Através desta posição editorial ideológica, a imprensa alternativa, como era denominada, recriou a produção jornalista da época, ao buscar criar um sistema de comunicação para a população negra, onde as questões raciais fossem abordadas. Tratava-se, segundo Rosa (2014) “de uma estratégia política de interferir na esfera pública na busca pelo poder de influência e emissão de opinião própria, no sentido de participação política, e de travar uma luta ideológica através da imprensa negra (ROSA, 2014, p. 557)".

Configurando-se em um dos mais importantes periódicos desta imprensa negra brasileira, o jornal Quilombo: Vida e aspirações do negro (10 números, entre 19481950) destacou-se pelo diferente formato que apresentava. Segundo Guimarães, Quilombo iria além das funções tradicionais desempenhadas pela imprensa negra alternativa, como criar uma atmosfera de reconhecimento e sociabilidade para a classe média negra. Produzidos pelos intelectuais e ativistas Abdias Nascimento ${ }^{4}$ e Guerreiro $\operatorname{Ramos}^{5}$, "Quilombo inaugura uma real inserção da intelligentsia negra brasileira na vida nacional, negra não apenas na cor, mas, e principalmente, na identidade (GUIMARÃES, 2003, p. 266)".

Desde seu princípio, o jornal Quilombo assumiu a proposta de ser um veículo de divulgação das ações do Teatro Experimental do Negro. Nascidos num contexto de embranquecimento cultural, o Quilombo trazia em seu cerne a gênese do TEN: a luta contra a discriminação racial. O Teatro Experimental do Negro - TEN nasceu em 1944 no Rio de Janeiro, com a proposta de resgate dos valores da humanidade e da cultura negro-africana que foram destruídos e negados pela colonização. O TEN projetava a

\footnotetext{
4 Abdias Nascimento (1914-2011) foi poeta, ator, dramaturco, escritor, artista, plástico, professor universitário, político e ativista dos direitos civis e humanos das populações negras. Considerado um dos maiores expoentes da cultura negra no Brasil e no mundo, fundou entidades pioneiras como o Teatro Experimental do Negro (TEN), o Museu da Arte Negra (MAN) e o Instituto de Pesquisas e Estudos AfroBrasileiros (IPEAFRO). Foi um idealizador do Memorial Zumbi e do Movimento Negro Unificado $(\mathrm{MNU})$ e atuou em movimentos nacionais e internacionais como a Frente Negra Brasileira, a Negritude e o Pan-Africanismo.

5 Aberto Guerreiro Ramos (1915-1982) foi uma figura de grande relevo da ciência social no Brasil. Oriundo do recôncavo da Bahia, o intelectual foi deputado federal pelo Rio de Janeiro e membro da delegação do Brasil junto à ONU. É autor de dez livros e de numerosos artigos, muitos dos quais têm sido disseminados em inglês, francês, espanhol e japonês.
} 
valorização social negra no Brasil, por meio da educação, cultura e arte. Como nos mostra Abdias Nascimento

Fundando o Teatro Experimental do Negro em 1944, pretendi organizar um tipo de ação que a um tempo tivesse significação cultural, valor artístico e função social. De início, havia a necessidade do resgate da cultura negra e seus valores, violentados, negados, oprimidos e desfigurados. O negro não deseja a ajuda isolada e paternalista, como um favor especial. Ele deseja e reclama um status elevado na sociedade, na forma de oportunidade coletiva, para todos, a um povo com irrevogáveis direitos históricos. A abertura de oportunidades reais de ascensão econômica, política, cultural, social, para o negro, respeitando-se sua origem africana (NASCIMENTO. A apud NASCIMENTO. E. 1981, p.188).

Através do jornal Quilombo, o TEN procurou defender as suas ideias sobre o Brasil, e divulgar os projetos empreendidos pelo grupo, assim como abrir espaço para todos que estavam pensando as relações raciais no Brasil. Entre seus objetivos e propostas, divulgados na terceira página em um espaço denominado "Nosso Programa", que aparece até a $5^{\circ}$ edição, o jornal Quilombo destaca seu papel no combate ao "preconceito de cor e de raça" no Brasil. Pleiteando que fosse previsto e definido o crime de discriminação racial nos códigos penais brasileiros, o jornal rompe com o ideal de paraíso racial propagado à época. Ao apresentar o jornal, Abdias nos diz,

Nós saímos - vigorosa e altivamente - ao encontro de todos aqueles que acreditam, - com ingenuidade ou malícia -, que pretendemos criar um problema no país. A discriminação de cor e de raça no Brasil é uma questão de fato. Porém a luta de QUILOMBO não é especificamente contra os que negam os nossos direitos, senão em especial para fazer lembrar ou conhecer ao próprio negro os seus direitos à vida e à cultura. A cultura, com intuição e acentos africanos, a arte, poesia, pensamento, ficção, música, como expressão étnica do grupo brasileiro mais pigmentado, paulatinamente vai sendo relegada ao abandono, ridicularizada pelos líderes do "branqueamento" (QUILOMBO, nº 1 , 1948, p. 1).

Com periodicidade mensal, Quilombo tinha como colunas permanentes: Democracia racial, Fala A Mulher, Negros na História, Livros, Tribuna Estudantil, Escolas de samba, Notícias do Teatro Experimental do Negro, Cinema, Música, Rádio, Cartaz, Sociais, Close up e números de matérias assinadas. As matérias assinadas e a coluna Democracia racial caracterizavam-se por ser um espaço aberto a reflexões 
acerca das relações raciais brasileiras, publicava-se geralmente com exclusividade textos de Roger Bastide, Arthur Ramos, Gilberto Freyre, Hamilton Nogueira, Ironildes Rodrigues, Guiomar Ferreira Maria Nascimento entre outros.

A discussão acerca da democracia racial era valiosa para o jornal Quilombo. Segundo Domingues (2008), o ideal da democracia racial atravessou vários números do jornal, que se mantinha aberto a diferentes perspectivas sobre o fenômeno brasileiro. Segundo Kabengele Munanga, “Quilombo congregava, num mesmo espaço político e cultural, intelectuais negros e brancos, que possuíam uma visão crítica sobre o racismo e a situação do negro brasileiro (MUNANGA; GOMES, 2006, p.122)”. Aponta-se que tal postura adotada pelo jornal eximia-o de uma imagem de intolerância ou parcialidade junto à opinião publica (DOMINGUES, 2008). Neste sentido, é interessante pontuar que a primeira matéria da coluna Democracia racial, fora justamente assinada por Gilberto Freyre, um dos porta-vozes da democracia étnica. Em seu texto "Atitude brasileira", Freyre nos diz:

Não há exagero em dizer-se que no Brasil vem se definindo uma democracia étnica contra a qual não prevaleceram até hoje os esporádicos arianismos ou os líricos, embora às vezes sangrentos melanismos que, uma vez por outra, se têem manifestado entre nós. Há decerto entre os brasileiros preconceito de cor. Mas estão longe de constituir o ódio sistematizado, organizado, arregimentado, de branco contra preto ou de ariano contra judeu ou de indígena contra europeu que se encontra em outros países de formação étnica e social semelhante à nossa. [Freyre encerra seu texto argumentando ainda que] "devemos estar vigilantes, os brasileiros de qualquer origem, sangue ou cor, contra qualquer tentativa que hoje se esboce no sentido de separar, no Brasil, "brancos" de "africanos" (FREYRE, Quilombo no. 1. dez. de 1948.)

A perspectiva esboçada por Gilberto Freyre, como citado anteriormente, era um pensamento comum aos intelectuais que buscavam compreender as relações raciais brasileiras. Por meio do que atualmente conhecemos como "mito da democracia racial", instaurou-se um senso comum de que não existiria um racismo sistematizado no Brasil, mas sim meramente um "preconceito de cor". Comparando as dinâmicas raciais brasileiras com os sistemas de segregação racial dos estado-unidenses, teóricos afirmavam que no Brasil era encontrada uma forma mais branda do racismo, que poderia ser visualizada pelo alto índice de miscigenação da população. Tais perspectivas 
além de invisibilizar as formas e nuances pela qual o racismo se reconstruiu nas relações brasileiras, impossibilitava que a população criasse uma consciência racial e enxergasse as dinâmicas herdadas da colonização.

Assim como o TEN, Quilombo contestava este olhar racialmente democrático e partilhava das mesmas convicções na luta antirracista. Segundo Costa (2015), na edição de estreia do Quilombo, no texto Nós reafirma-se o compromisso coma denúncia da existência do racismo no Brasil e negação da harmonia social promovida pela tão difundida democracia racial. $O$ folhetim trabalhava para que segregações raciais não institucionalizadas fossem problematizadas e reconhecidas publicamente, como nos mostra Raquel de Queiroz $^{6}$ em seu artigo publicado na coluna Arquivo do jornal Quilombo:

Será que por ausência de preconceito que quase nenhuma das ordens religiosas existentes no Brasil recebe pessoas de cor no seu seio - salvos como leigos, que dizer, como criados? E que os colégios grã-finos não aceitam alunos ou alunas de cor? E que a Light (e o governo fecha os olhos ante isso) não admite telefonistas de cor? E que nenhuma loja das ditas elegantes daqui do Rio, de São Paulo e de outras capitais, emprega vendedores de cor? Já viu manicuras e cabeleireiras de cor nos salões de beleza de luxo? Leu no livro de Mário filho o que foi a batalha para se introduzirem jogadores negros nos clubes de futebol carioca? Sabe que nenhum bar da área atlântica, em Copacabana, permite que se sente às suas mesas algum freguês de cor? E que a restrição era feita no cassino - e ainda é feita em certas "boites" ou cabarés de alta sociedade? E que tanto o hotel Serrador como outras hospedarias de alto bordo adotam como linha de conduta não tolerar hóspedes de cor... [...] Se isso não é discriminação racial e, mais grave ainda, discriminação admitida e amparada pelo governo - que nome lhe daremos? (QUEIROZ, Quilombo, dez de 1948 p.2).

Para o autor Petrônio Domingues “o artigo de Raquel de Queiroz traçava um painel panorâmico do regime não declarado de segregação racial a que o negro ficava exposto em vários lugares do Brasil, na década de 1940 (DOMINGUES, 2008, p. 266)”. Ao demonstrar como o racismo estava presente nas diversas situações do cotidiano brasileiro, a estratégia adotada pelo jornal é a de revelar a hipocrisia e contradições da democracia racial. Em seu texto "Queremos estudar" escrito para o jornal Quilombo, o ator Haroldo Costa, revela como o racismo operava no sistema educacional brasileiro.

\footnotetext{
${ }^{6}$ Rachel de Queiroz foi uma tradutora, romancista, escritora, jornalista, cronista prolífica e importante dramaturga brasileira. Autora de destaque na ficção social nordestina. Foi a primeira mulher a ingressar na Academia Brasileira de Letras. Em 1993, foi a primeira mulher galardoada com o Prêmio Camões.
} 
Aponta-se que além da falta de recursos financeiros, os alunos negros enfrentavam a barreira racial quando as diversas escolas não permitiam admissão destes em seus quadros discentes. O ator ainda denunciou casos explícitos, como o de jovens negros que foram vedados de efetivarem suas matrículas em escolas militares ao serem reprovados em exames médicos mesmo sem terem problemas de saúde (MILES, 2017)

O folhetim fazia tal alerta para o racismo dentro do sistema educacional, pois a exclusão da população negra reproduzia e condicionava negros/as a ocuparem lugares subalternizados na sociedade moderna. Lutando contra esta corrente, Quilombo publicava frequentemente matérias divulgando iniciativas comunitárias de ensino e alfabetização. Segundo Elisa Larkin, "todos os números do Quilombo, com a única exceção do $\mathrm{n}^{\circ} 2$, trazem noticias ou comentários sobre a questão do ensino, da educação e/ou de iniciativas de educação comunitária (NASCIMENTO. E, 2003, p.292)”.

$O$ jornal Quilombo assumia o lema de "educação para o negro e reeducação para o branco". Compreendendo que a questão racial era de interesse comum na sociedade, não um "problema do negro", o jornal almejava representar uma fonte de consciência racial para a população negra e um principio de reeducação para o branco, buscando desfazer sua ideologia racial discriminativa (NASCIMENTO, E, 2003).

Cumprindo este propósito, na coluna Arquivo publicava-se regularmente matérias e textos que elucidassem a questão racial no Brasil através da perspectiva do negro brasileiro. Por meio desta coluna, tanto a população negra quanto todos que tivessem acesso ao jornal, eram incentivados a refletir sobre as formas que o racismo estruturava a vida da população negra. Em sua pertinente colocação no texto "Os arianos de Criciuma", Origenes Lessa ${ }^{7}$ nos convida a refletir sobre o ideal da democracia racial e a realidade do negro brasileiro:

Fala-se, com muito ufanismo, em nossa democracia racial. Haverá mesmo? Desconhecemos o preconceito de cor? Negros, mulatos, semi-brancos, têm no Brasil, os mesmos direitos na prática, entram em toda parte, vivem como gente? Há quem diga que sim. Há quem nos inveje essa imaginária ausência de preconceitos. Porque é imaginária. No fundo, temos prejuízos semelhantes aos dos americanos do norte, apenas atenuados em virtude do compromisso geral

\footnotetext{
${ }^{7}$ Orígenes Temudo Lessa foi um jornalista, contista, novelista, romancista e ensaísta brasileiro. Um dos imortais da Academia Brasileira de Letras e autor de importantes obras da literatura brasileira do século $\mathrm{XX}$.
} 
com o sangue negro. [...] Na realidade, para o negro, e seus descendentes, poucas portas além dos serviços humildes, do rádio e de outras carreiras, estão francamente abertas. Só muito talento e acidentes de formatura dão ao negro e ao mulato no Brasil o direito de entrar num salão elegante não para servir, mas para ser servido também. E a prova mais evidente de que existe entre nós o preconceito de cor está em nossa pitoresca fuga para a brancura (LESSA, QUILOMBO, jun. 1949).

Ao tempo em que confrontava os equívocos da democracia racial, Quilombo buscava uma conscientização coletiva dos condicionamentos sociais que eram impostos à população negra. Por meio das denúncias dos casos de "preconceito racial", o folhetim comprovava segundo Petrônio Domingues que "o problema do negro no Brasil tinha natureza racial, fundamentalmente, e social, secundariamente. Nesse sentido, os negros eram vítimas de racismo independentemente de sua condição social. (DOMINGUES, 2008: 279)".

\section{QUILOMBO: CULTURA E NEGRITUDE BRASILEIRA EM ASCENSÃO}

Além de promover uma conscientização racial no Brasil, o jornal Quilombo trabalhava na edificação de uma cultura negra no país. Em seus estudos sobre a imprensa negra, Guimarães (2003) nos informa que o objetivo de Quilombo, iria além do reconhecimento político e do combate ao preconceito racial, buscava-se também uma vinculação com as raízes africanas da cultura nacional.

Através de uma perspectiva afro centrada da agencia humana, dentro das páginas do jornal dava-se prioridade à construção de uma valorização da matriz cultural afro-brasileira. Além de reservar um espaço para as manifestações da cultura afrobrasileira, como o candomblé, “o jornal publicava e discutia música, o cinema, o teatro e a poesia feitos no Brasil por negros já inseridos no mercado artístico nacional, e que tratam de temáticas que interessam aos negros (GUIMARÃES, 2003, p. 265)”.

Focados em reconstruir a identidade negro-africana no país, e em sintonia com o mundo cultural brasileiro e internacional, o folhetim foi pioneiro ao abordar as propostas de movimentos culturais da diáspora africana como a Négritude Francofa.

Revista da ABPN • v. 12, n. Ed. Especial - Caderno Temático: "Africanos, escravizados, libertos biografias, imagens e experiências atlânticas” • agosto de 2020, p. $694-710$ 
Liderado por intelectuais como Aimé Césarie ${ }^{8}$ e Léopold Sédar Senghor ${ }^{9}$, a Négritude comprometia-se através da linguagem e da literatura, a transformar o sentido depreciativo da palavra Negro. Sob as bases da identidade (pertencimento negro), fidelidade (engajamento com a África) e solidariedade (ligação com a diáspora africana), ressignificou o pertencimento a raça negra.

A Negritude como movimento poético cultural e político-social desempenhou um importante papel histórico, de vital importância no processo de descolonização das colônias europeias em África, levado a cabo no período pósguerra (a partir de 1945), na emergência e consolidação de literaturas de países africanos e literaturas afras descendentes e também como instrumento de conscientização do negro em diáspora, através da desconstrução de estereótipos seculares atribuídos a ele, levando o à construção de uma nova identidade e à reivindicação dos direitos a eles negados durante séculos (SANTOS, 2007, p. 7)

Simpáticos aos ideais de orgulho negro apresentados pelo movimento négritude, nos números seguintes do Quilombo, a revista da diáspora africana ganhou destaque e foi largamente difundida nas páginas do jornal. Segundo Guimarães, Quilombo teria desempenhado um papel fundamental na divulgação da Revista Présence Africaine no Brasil, principal publicação do movimento négritude, que influenciou os movimentos do pan-africanismo e da descolonização no continente africano. Em seu primeiro número, Quilombo trazia uma nota informativa acerca do lançamento da revista Présence Africaine como forma de tornar a comunidade brasileira ciente de sua existência.

Não temos notícia de outra publicação negra que iguale em importância cultural a essa "Présence Africaine", editada em Paris e Dakar. O escritor mundialmente famoso André Gide, - que ao lado de Albert Camus, Richard Wright, Jean-Paul Sartre, e outros - figura como patrono da revista, fez a apresentação num artigo apelando para se ouvisse o que o negro tinha a dizer, desde que há tantos séculos ele vinha sendo explorado sem uma oportunidade. E os negros da Sorbonne, em Paris, ou de Dakar, Cuba, Haiti ou Norte-Americanos estão dizendo coisas graves, seríssimas, decisivas a respeito dos temas mais variados que interessam ao comportamento do homem intelectual, vinculado à marcha

\footnotetext{
${ }^{8}$ Aimé Fernand David Césaire (1913-2008) foi um poeta, dramaturgo, ensaísta e político.da negritude. tornou-se, com Léopold Sédar Senghor, um dos pioneiros da literatura negra em França.

${ }^{9}$ Léopold Sédar Senghor (1906-2001) foi um político e escritor senegalês. Foi presidente de Senegal, de 1960 a 1980. Foi entre as duas Guerras Mundiais, juntamente ao poeta antilhano Aimé Césaire, ideólogo do conceito de negritude
} 
perene do espírito e do pensamento em sua inquietude e insatisfação criadora. [...] "Présence Africaine" está em seu quarto número de revista mensal significando o primeiro passo numa distância nova, uma etapa histórica na influência do pensamento negro na evolução do mundo (NASCIMENTO. E, 2003, p.21).

Elisa Larkin nos informa que Quilombo publicava notas e peças publicitárias da revista e, posteriormente, durante o $1^{\circ}$ Festival Mundial de Artes Negras, O TEN também ganharia destaque na Presence Africaine ao publicar sua nota de protesto contra os critérios utilizados pelo Itamaraty, para constituir a delegação brasileira e inviabilizar a participação da organização brasileira no evento pan-africanista. Além disso, em seu terceiro número, o jornal Quilombo publicou o ensaio “Orfeu Negro” de Jean-Paul Sartre $^{10}$ e posteriormente o artigo de Roger Bastide ${ }^{11}$ sobre "O movimento negro francês", ambos sob a tradução de Ironildes Rodrigues que nos diz:

O manifesto desses epígonos da Negritude foi difundido pelo mundo todo. Uma revista que expressava tão bem essa pregação apostólica e doutrinária, Présence Africaine, trouxe até aquele depoimento impressionante de um Jean-Paul Sartre, Orphée noir, que eu fui o primeiro a traduzir, nas páginas de um outro órgão do pensamento mais elevado da negritude brasileira: Quilombo. Nesse jornal tão sério e compenetrado do Teatro Experimental do Negro de Abdias do Nascimento é que foi divulgado todo o pensamento socialista e de união de todos os homens de cor do mundo, apregoado por Léopold Sédar Senghor. (RODRIGUES, 1997, p. 255-256).

Sensível ao cenário internacional do mundo africano, a discussão sobre negritude no seio do TEN e do Quilombo, partia da referência ao movimento poético dos africanos e antilhanos de língua inglesa. Porém, o conceito de negritude elaborado por eles não se resumia a uma transposição das ideias e propostas do movimento francês para o Brasil, pelo contrário, "tratava-se, em primeiro lugar, de uma identificação com a origem africana e com a condição do negro no contexto brasileiro, articulada em termos próprios à realidade nacional (NASCIMENTO. E, 2003, p 311)”.

\footnotetext{
10 Jean-Paul Sartre (1905-1980) foi um escritor, roterista e filósofo existencialista francês. O existencialismo de Sartre foi uma das correntes mais importantes do pensamento francês.

${ }^{11}$ Roger Bastide (1898-1974) foi um sociólogo e antropólogo com incursões pela critica literária e psicologia social. É responsável por vasta obra, parte dela dedicada ao Brasil, onde viveu, como professor da Universidade de São Paulo, entre 1938-1954.
} 
Considerando a importância da narrativa da negritude para o processo de recuperação do povo negro brasileiro, Quilombo em conjunto com TEN imprimiu esta valorização da identidade cultural africana em suas matrizes. Como porta-voz do TEN, Quilombo trazia à tona uma quantidade surpreendente de intervenções políticas, educacionais e culturais que serviam de estimulo ao protagonismo social, cultural e político da população negra.

O jornal divulgou ações como: os cursos de alfabetização e iniciação cultural (1944 e 1946), os concursos de beleza Rainha das Mulatas e Boneca de Pixe (1947 a 1950), o concurso de artes plásticas Cristo Negro (1955), entre outros projetos que se baseavam no fortalecimento da identidade negra e da matriz cultural africana. Segundo Nascimento, enfrentando o tabu da democracia racial, O TEN e a consequentemente Quilombo eram os únicos a "encampar consistentemente a linguagem e postura política da négritude, no sentido de priorizar a valorização da personalidade e cultura especificas ao negro como caminho de combate ao racismo (NASCIMENTO, 2004, p.78)".

Inspirados no orgulho e nacionalismo negro oriundos da négritude, o jornal Quilombo divulgava os projetos políticos e as candidaturas negras como meio de fortalecimento comunitário negro. Segundo Elisa Larkin, Quilombo oferecia espaço a todos os candidatos negros, de forma suprapartidária. Por meio de uma carta aos partidos políticos, Quilombo requisitava os contatos dos candidatos negros, a fim de promover suas candidaturas gratuitamente. Em uma destas matérias o folhetim afirma que: "Até ontem o negro brasileiro foi um joquete, um instrumento de cabos eleitorais, um inconsciente do deu próprio valor para atuar no sentido de conseguir melhorias para sua gente. Mas isso foi ontem. Hoje ele sabe que seu voto pode decidir muitas coisas (QUILOMBO apud NASCIMENTO, p. 299)”.

Através destas ações o Quilombo e do TEN, apresenta a négritude para os brasileiros como "uma rearticulação da afirmação dinâmica da identidade afrodescendente no processo de resistência ao holocausto escravista (NASCIMENTO. E, 2003, p. 315)". Ao escrever ao Quilombo sobre a negritude, Guerreiro Ramos nos diz: "No momento em que lançamos na vida nacional o mito da negritude, fazemos questão de proclamá-la com toda clareza. A negritude não é um fermento de ódio. Não é

Revista da ABPN • v. 12, n. Ed. Especial - Caderno Temático: "Africanos, escravizados, libertos biografias, imagens e experiências atlânticas" • agosto de 2020, p. 694-710 
um cisma. É uma subjetividade. Uma vivência. (RAMOS, Quilombo, n. 10, junhojulho/1950, p. 11)”.

O folhetim se engajava na edificação de uma psicopedagogia que abordasse a construção da identidade e autoestima do negro brasileiro. Por meio da divulgação de projetos culturais, notícias, reportagens, e iniciativas de educação comunitária, que eram acompanhados de uma reflexão sobre a identidade afrodescendente num contexto de branquitude, o jornal Quilombo tornou se um veículo poderoso de educação popular, responsável pela formação de uma negritude brasileira e nacionalista (GUIMARÃES, 2003).

\section{CONSIDERAÇÕES FINAIS}

Embora o Jornal Quilombo tenha atuado apenas ao longo de três anos (19481950), é notável a importância do mesmo na luta contra a discriminação racial e na construção de uma identidade afro-diaspórica. Por meio de suas colunas e editoriais, Quilombo incentivava uma conscientização racial da comunidade negra ao tempo em que produzia meios para uma reeducação social para a sociedade brasileira. Seus textos denunciavam o racismo que negros brasileiros sofriam cotidianamente e contrapunham a narrativa de paraíso racial adotado por intelectuais brancos e pela sociedade em geral.

Através de suas ações antirracistas, o jornal Quilombo: Vida, problemas e aspirações do negro, foi além do papel atribuído às mídias alternativas colocando-se como uma organização política dedicada a produzir umas práxis intelectual acerca da identidade negra no Brasil. Conforme foi possível constatar neste ensaio, Quilombo promoveu as vozes de intelectuais negros que tinham suas reflexões raciais invisibilizadas pela mídia tradicional, bem como possibilitou que debates afrodiaspóricos, como a Négritude, fossem acessados e reinventados pela comunidade afrobrasileira. Certamente, podemos concluir que o deixado pelo legado do jornal Quilombo exprime a fonte de mobilização racial que o folhetim se tornou no século XX.

\section{REFERÊNCIAS BIBLIOGRÁFICAS}

Revista da ABPN • v. 12, n. Ed. Especial - Caderno Temático: "Africanos, escravizados, libertos biografias, imagens e experiências atlânticas" • agosto de 2020, p. $694-710$ 
BASTIDE, Roger. A Imprensa Negra do Estado de São Paulo. Estudos Afro-Brasileiros. São Paulo: Perspectiva, 1983, p.129-156.

BARBOSA, Muyatan.; COSTA, Thayná Gonçalves dos Santos da. Negritude e pan-africanismo no pensamento social brasileiro: A trajetória de Ironildes Rodrigues (1923-1987) Revista Brasileira de Ciências Sociais. Vol.34. n.100, 2019.p.1-20.

COSTA, Sérgio. A construção sociológica da raça no Brasil. Estudos Afro-asiáticos, Ano 24, $\mathrm{n}^{\circ}$ 1,2002 , p.35-61.

COSTA, Guilherme Souza. Uma leitura sociocrítica do jornal Quilombo: vida, problemas e aspirações do negro (1948-1950). Dissertação (Mestrado em Ciências Sociais), Universidade Estadual de Londrina, Lodrina, 2015.

CUNHA, Vanessa Lima. As muitas vozes presentes na coluna Arquivo do jornal Quilombo: Vida, problemas e aspirações do negro (1948-1950). Anais do IV Encontro Nacional de Estudos da Imagem- I Encontro Internacional de Estudos da Imagem, Londrina, 2013, p.239.

Quilombo: a voz do teatro experimental do negro (Rio de Janeiro, 1940/1950). Revista Cadernos de Clio, , nº3 v. II, p. 283-300, 2012.

DOMINGUES, Petronio. Quilombo (1948-1950): uma polifonia de vozes afro-brasileiras. Revista Ciências \& Letras, $\mathrm{n}^{\circ}$ 44, 2008, p.261-289.

Movimento negro brasileiro: alguns apontamentos históricos. Revista Tempo, vol.12, n.23,p.100-122,2007.

FREIRE, Luis Thiago. O pan-africanismo em Abdias Nascimento e a proposta de descolonização. Revista da Associação Brasileira de Pesquisadores/as Negros/as (ABPN), [s.I], v.12, n.31, fev.2020.

GUIMARÃES, Antônio Sergio Alfredo. Classes, raças e democracia. São Paulo: Ed.34, 2002.232p.

Depois da democracia racial. Tempo Social, Revista de Sociologia da USP, v.18, n.2, 2006, p.269-287.

Notas sobre raça, cultura e identidade na imprensa negra de São Paulo e Rio de Janeiro, 1925-1950. Revista Afro-Ásia, no 29/30, 2003, p.247-269.

MILES, Tshombe. Abdias Nascimento e a tradição intelectual afro-diaspórica: no combate ao racismo. Revista de Ciências Sociais. v.48, n.2,p.106-136, jul./dez,2017.

MUNANGA, Kabengele; Gomes, Nilma Lino. O negro no Brasil de hoje. São Paulo: Editora Global, 2006, 224p.

NASCIMENTO, Abdias do. Teatro Experimental do Negro: trajetória e reflexões. Estudos Avançados. Vol.18, $\mathrm{n}^{\circ}$ 50, 2004, p.209-224.

O Negro Revoltado. 2a ed. Rio de Janeiro: Nova Fronteira, 1982 (1968).

O Brasil na Mira do Pan-africanismo. Salvador: EDUFBA, 2002,344p

NASCIMENTO, Elisa Larkin. O Sortilégio da cor: identidade, raça e gênero no Brasil. São Paulo: Selo Negro, 2003, 412p.

Revista da ABPN • v. 12, n. Ed. Especial - Caderno Temático: "Africanos, escravizados, libertos biografias, imagens e experiências atlânticas” • agosto de 2020, p. $694-710$ 
Pan-africanismo na América do Sul: Emergencia de uma rebelião negra. Petrópolis: Ed. Vozes em co-edição com Instituto de Pesquisas e Estudos Afro-brasileiros (IPEAFRO), 1981.

NASCIMENTO, Abdias.; NASCIMENTO, Elisa Larkin. Quilombo vida, problemas $e$ aspirações do negro. São Paulo: Ed.34, Edição Fac-similar, 2011, 128p.

NUNES, Tailane Santana: Pan-Africanismo E Libertação. A Luta Anti-Colonial de Abdias do Nascimento. Idealogando: Revista de Ciências Sociais da UFPE, v. 2, n. 1, 2018.

PINTO, Ana Flávia Magalhães. De pele escura à tinta preta - a imprensa negra no século XIX (1833-1899). Dissertação (Mestrado em História), Universidade de Brasília, Brasília, 2006.

QUEIROZ, Raquel. Linhas de cor. Quilombo vida, problemas e aspirações do negro, Rio de Janeiro, Dez de 1948, Nº1, Coluna Arquivo: p. 2.

RODRIGUES, Ironides. (1997a), Sebastião Rodrigues Alves e a inquietação social do negro brasileiro. Revista Thoth (Gabinete do Senador Abdias Nascimento), n², p. 251-281.

ROSA, Daniela Roberta Antônio. Teatro Experimental do Negro: estratégia e ação. Dissertação (Mestrado em Sociologia ) Universidade Estadual de Campinas, 2007, 180p.

ROSA, Isabel Cristina Clavelin da Rosa. Impensa Negra: descobertas para o jornalismo brasileiro. Estudos em jornalismo e mídia. Vol. 11, № 1, 2014, p.555-568.

SANTOS, Donizeth Aparecido dos Santos. Pan-africanismo e movimentos culturais negros. Revista Analecta, V.8, nº1, 2007, p.66-77.

Recebido 03/07/2020

Aprovado em 22/07/2020

Revista da ABPN • v. 12, n. Ed. Especial - Caderno Temático: "Africanos, escravizados, libertos biografias, imagens e experiências atlânticas" • agosto de 2020, p. $694-710$ 